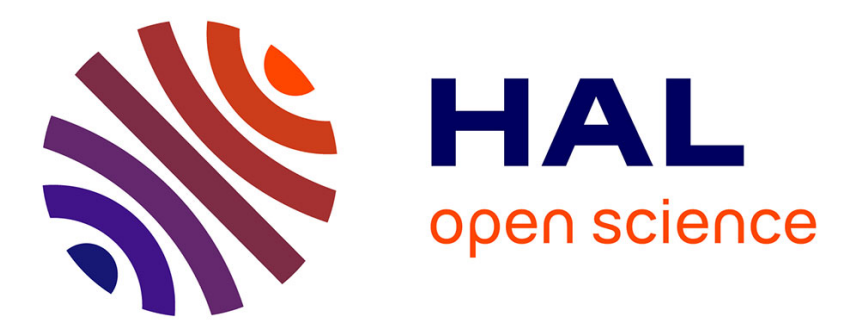

\title{
Impact of corticosteroids on experimental meningococcal sepsis in mice.
}

\author{
Michael Lévy, Michaël Levy, Ana Antunes, Laurence Fiette, Ala-Eddine \\ Deghmane, Muhamed-Kheir Taha
}

\section{- To cite this version:}

Michael Lévy, Michaël Levy, Ana Antunes, Laurence Fiette, Ala-Eddine Deghmane, et al.. Impact of corticosteroids on experimental meningococcal sepsis in mice.. Steroids, 2015, 101, pp.96-102. 10.1016/j.steroids.2015.05.013 . pasteur-02013271

\section{HAL Id: pasteur-02013271 \\ https://hal-pasteur.archives-ouvertes.fr/pasteur-02013271}

Submitted on 30 Mar 2019

HAL is a multi-disciplinary open access archive for the deposit and dissemination of scientific research documents, whether they are published or not. The documents may come from teaching and research institutions in France or abroad, or from public or private research centers.
L'archive ouverte pluridisciplinaire HAL, est destinée au dépôt et à la diffusion de documents scientifiques de niveau recherche, publiés ou non, émanant des établissements d'enseignement et de recherche français ou étrangers, des laboratoires publics ou privés.

\section{(이)( $)$}

Distributed under a Creative Commons Attribution - NonCommercial - NoDerivatives 44.0 


\title{
Impact of corticosteroids on experimental meningococcal
}

\author{
sepsis in mice
}

Michaël Levy ${ }^{1}$, Ana Antunes ${ }^{1}$, Laurence Fiette ${ }^{2}$, Ala-Eddine Deghmane ${ }^{1}$ and Muhamed-Kheir $\mathrm{Taha}^{1 *}$

Institut Pasteur, ${ }^{1}$ Unité des Infections Bactériennes Invasives and ${ }^{2}$ Unité Histopathologie Humaine et Modèles Animaux, 28 rue du Dr Roux, 75724 Paris cedex 15, France and Université Paris Descartes, Sorbonne Paris, Cité, France

\author{
*For correspondence \\ mktaha@pasteur.fr \\ Tel +3314568 8438 \\ Fax +33145688338
}




\section{HIGHLIGHTS}

- Meningococcal sepsis is associated with strong inflammation and high fatality.

- Corticosteroids adjuvant treatment can be used to reduce inflammatory response.

- Clinical trials are difficult to conduct but animal models can substitute.

- Corticosteroids-treated mice showed better clinical and inflammatory scores.

- Interleukin 10 was early induced and could be responsible for this positive impact. 


\section{ABSTRACT:}

Neisseria meningitidis is responsible for septicemia and meningitis with high fatality that is associated with an excessive inflammatory reaction particularly with hyperinvasive isolates of the clonal complex ST-11 (cc11). However, anti-inflammatory adjuvant treatment remains controversial and difficult to assess in patients. We addressed this topic in a well-defined experimental meningococcal infection in transgenic mice expressing the human transferrin. Mice were infected by intra-peritoneal challenge with bioluminescent serogroup C/cc11 strain. After 3 hours of infection mice were differentially treated every 6 hours by saline, amoxicillin alone or amoxicillin and dexamethasone (DXM). Infected mice were scored for clinical status, temperature and weight. Biological markers of inflammation were also quantified.

Significant clinical improvement was observed in mice treated with amoxicillin and DXM compared to the two other groups. A significant reduction of the inflammatory reaction assessed by CRP and Lipocalin 2 (two acute phase proteins) was also observed with this treatment. DXM significantly increased blood levels of IL-10 at six hours post-infection. DXM/amoxicillin treated mice, compared to the two other groups, also showed lower levels of TNF- $\alpha$ and lower bacterial blood load assessed by serial dilutions of blood and bioluminescence dynamic imaging. Our results suggest that DXM, added to an appropriate antibiotic therapy, has a beneficial effect on experimental sepsis with a hyperinvasive meningococcal strain in transgenic mice expressing human transferrin. This is most likely due to the reduction of inflammatory response by an early induction of IL-10 cytokine. These data may allow better decision-making to use or not corticotherapy during meningococcal sepsis.

Keywords: Meningococcus, corticosteroids, sepsis, inflammation, cytokine, mice 


\section{INTRODUCTION}

Neisseria meningitidis $(\mathrm{Nm})$ is frequently encountered in the nasopharynx of asymptomatic carriers but is also responsible for severe invasive infections that are a major cause of morbidity and mortality worldwide. Meningococcal isolates are variable, belong to several genotypes and express diverse phenotypes [1]. Genetic analyses of meningococcal populations by multilocus sequence typing (MLST) clusters meningococcal isolates in clonal complexes (cc). Invasive isolates belong to few clonal complexes called "hyperinvasive genotypes (in Europe cc8, cc11, cc32, cc41/44 and cc269) [1]. However, no specific sets of genes were identified so far to be directly responsible for the pathogenesis of hyper-invasive isolates of $\mathrm{Nm}$. Nevertheless, several bacterial factors were shown to be involved in meningococcal virulence such as the pili, the polysaccharidic capsule as well iron acquisition [2]. Genotypes rather than the capsule group of meningococcal isolates are suggested to be, at least partially, involved in determining the outcome of host-bacteria interaction. Indeed, isolates of the cc11 are significantly associated with the fatal outcome of the disease [3, 4]. cc11 isolates were also reported to induce more apoptosis than carriage isolates or invasive isolates belonging to other $\mathrm{cc}[4,5]$.

During infection, Nm releases microbial associated molecular patterns (MAMPs) such as lipooligosaccharide (LOS) and peptidoglycan that induce up-regulation of pro-inflammatory cytokines (like tumor necrosis factor $\alpha(\mathrm{TNF}-\alpha)$ and interleukin 1 and 6 (IL-1, IL-6)) as well as a down-regulation of anti-inflammatory cytokines (like IL-1 $\beta$, IL-10 or soluble receptor to TNF- $\alpha$ ) and this has been shown to be essential in the evolution of meningococcemia [6].

Corticosteroids are strong anti-inflammatory drugs whose action pass through the modulation of the expression of genes involved in the inflammatory reaction and can thus be used to reduce the uncontrolled inflammatory response $[7,8]$. The prescription of corticosteroids in IMI is controversial and this is mostly due to the fact that most of the studies include patients 
infected with different bacterial species and do not focus on genotypes of the bacterial isolates $[9,10]$. Interestingly, Madhi et al. [11] showed that in the absence of corticosteroids, there was a significant higher death rate in IMI in children infected with cc11 isolates compared to cases due to other cc. This difference disappeared in children who received corticosteroids. However, the timing of the treatment and the diverse genetic background of the patients may hinder definitive conclusions. A relevant animal model of meningococcal sepsis is available in transgenic mice expressing the human transferrin. Meningococci acquire iron for their growth during infection specifically from human sources such as the human transferrin [12]. This model allowed us to evaluate the impact of corticoids during meningococcal experimental infection in this defined model. 


\section{EXPERIMENTAL}

\subsection{Ethics statement}

This study was carried out in strict accordance with the European Union Directive 2010/63/EU (and its revision 86/609/EEC) on the protection of animals used for scientific purposes. Our laboratory has the administrative authorization for animal experimentation (Permit Number 75-1554) and the protocol was approved by the Institut Pasteur Review Board that is part of the Regional Committee of Ethics of Animal Experiments of Paris Region (Permit Number: 75-1554). All the invasive procedures were performed under anesthesia and all possible efforts were made to minimize animal suffering.

\subsection{Bacterial strains}

The strain 24198LUX is derived from the strain 24198 (serogroup C strain that belongs to ST11 clonal complex) $[13,14]$. The strain 2 C4-3LUX is derived from the strain $2 \mathrm{C} 4-3$ (serogroup $\mathrm{C}$ that belongs to the cc18) [15]. Both strains have been modified to be bioluminescent by the adjunction on the chromosome of the operon coding for the luciferase (luxCDABE) under the control of the promoter of porB (PrpoB) meningococcal gene as previously described [14]. We have previously shown that the insertion of the lux operon did not modify bacterial invasion in this animal model nor it modifies MIC of $\beta$-lactam antibiotics $[12,16]$.

\subsection{Mice, experimental infection and assessment}

Congenic $\mathrm{BALB} / \mathrm{c}$ transgenic mice expressing human transferrin were previously described [12]. Experimental meningococcal infections were performed in 8 week-old female BALB/c transgenic mice expressing human transferrin (hTf) by intra-peritoneal injection of 1 to $2.10^{7}$ 
CFU/mouse diluted in $0.5 \mathrm{ml}$ of saline. Mice were separated into three groups and were treated after three hours of infection: one group infected not treated, one group infected treated with amoxicillin (AMX) and one group infected treated with AMX and dexamethasone (DXM). The mice from the non-treated group received a $0.1 \mathrm{ml}$ intramuscular injection of saline in each thigh every six hours. Mice treated with AMX received a $0.1 \mathrm{ml}$ intramuscular injection of amoxicillin diluted in saline (Clamoxyl® forme injectable IM/IV 500mg) for a $50 \mathrm{mg} / \mathrm{kg}$ dose in one thigh and $0.1 \mathrm{ml}$ of saline in the other thigh. Mice treated with AMX and DXM received a $0.1 \mathrm{ml}$ intramuscular injection of DXM (dexamethasone sodium phosphate Mylan $4 \mathrm{mg} / \mathrm{ml}$ ) for a $0.15 \mathrm{mg} / \mathrm{kg}$ dose in one thigh and a $0.1 \mathrm{ml}$ injection of amoxicillin diluted in saline (Clamoxyl® forme injectable IM/IV 500mg) for a 50mg/kg dose in the other thigh. The three groups were injected every six hours for 48 hours after the first injection at three hours post-infection. One group of non-infected mice was also followed and received saline injection the same way as the non-treated group.

Clinical assessment was performed before bacteria inoculation, 3 hours, 6 hours, 12 hours, 24 hours, 36 hours and 48 hours post-inoculation. Mice weight was recorded and body temperature was measured transcutaneously using an infrared thermometer (BIOSEB® IR Rodent Thermometer, Vitrolles, France). A clinical score (ranging from 0 to 5 and adapted from those previously published $[17,18]$ was used to assess disease severity including fur aspect that ranged from 0 to $2(0=$ Erection of the hair, $1=$ Hair coat appears soiled, $2=$ Hair coat appears glossy and smooth) and activity score of living mice that ranged from 0 to 3 $(0=$ No resistance to traction, $1=$ Weak resistance to traction, $2=$ Strong resistance to traction, 3=Spontaneous forward propulsion). Blood was withdrawn from the retro-orbital plexus into heparinized tubes [19]. Bacteria load in blood was then evaluated by plating serial dilutions on GCB medium (Difco) supplemented with Kellog supplements [20] and results were expressed as colony forming units (CFU) per milliliter. In other sets of experiments, no blood 
samples were taken and meningococcal infection was followed by dynamic imaging as previously described [12]. Quantification was performed using total photons per second emitted by each mouse after 30 min, 3 hours, 6 hours and 24 hours post-infection by defining regions of interest.

\subsection{Cytokine immunoassays, CRP and full blood count}

Immunoreactive CRP, IL-6, KC, IL-10 and TNF- $\alpha$ were performed on blood samples using ELISA kit (R\&D Systems Europe) according to the manufacturer's recommendations. Total blood count was performed on $50 \mu \mathrm{l}$ of heparinized blood using Heska hematometer (Vet ABC Animal Blood Counter, Florida, USA).

\subsection{Detection of mouse Lipocaline 2 by Western Blot}

Heparinized plasmas were analyzed using Western Blot to detect the acute phase reactant protein, the Lipocalin 2 (Lcn2) as previously described [14]. The same positive control with a known concentration of Lcn2 was added to each Western blotting and used to quantify the Lcn2 concentration of each sample tested.

\subsection{Histological analysis}

Mice were euthanatized by intra-peritoneal $300 \mathrm{mg} / \mathrm{kg}$ injection of sodium pentobarbital. At necropsy, brain, spleen, liver, kidneys and adrenal glands were sampled, fixed in $4 \%$ buffered formalin, then routinely embedded in paraffin. $4 \mu \mathrm{m}$ sections were performed and stained with hematoxylin and eosin (H\&E). Histological findings were microscopically evaluated using a semi-quantitative score (1: minimal, 2: mild; 3: moderate, 4: marked, 5: severe). 


\subsection{Statistical analysis}

Results were expressed as means +/- standard deviations for the quantitative values and reproducibility was confirmed on two separated experiments. Statistical analyses were made using Prism 6® software (GraphPad Inc. San Diego, CA, USA). Comparison of data between 24198LUX strain and 2C4-3LUX strain were made using unpaired student's t-test. Variance analysis (two-way Annova) was used to compare the data of the three groups of treatment and a p-value $<0.05$ was considered as significant (taking into account the multiple comparisons). 


\section{RESULTS}

\subsection{Characteristics of the experimental infection in hTf transgenic mice using different meningococcal genotypes}

We first tested whether the characteristics of experimental sepsis in transgenic mice expressing the human transferrin show different kinetics according to the genotypes of the isolates. We therefore infected 8-week-old female BALB/c mice expressing hTf by $2 \times 10^{7}$ CFU intra-peritoneal injection of either strain 24198LUX (that belongs to the hyperinvasive genotype cc11) or 2C4-3LUX (that belongs to the non-hyperinvasive genotype cc18). Infection was monitored for $24 \mathrm{~h}$. Bioluminescent signals were similar for the two strains after 30 minutes and $3 \mathrm{~h}$ of infection. Dynamic bioluminescence imaging approach showed that after the intraperitoneal injection of the bacterial suspension, bacteria were spread to other organs such as the brain as confirmed by three-dimensional imaging (Supplementary Fig.S1 and video materials). Total body signals and signals of the skull (dorsal view) were higher for the 24198LUX strain $6 \mathrm{~h}$ after infection than for the 2C4-3LUX strain ( $\mathrm{p}=0.02$ and $\mathrm{p}=0.047$ respectively) (Fig. S1). Mice infected by the strain of the cc11 were more severely ill with significantly higher loss weight than mice infected by the cc18 isolate (data not shown). The levels of three cytokines (IL-6, KC and IL-10) were assessed on blood withdrawn $24 \mathrm{~h}$ after infection (Supplementary Table S1). Levels of IL-6, KC and IL-10 were significantly higher in mice infected with 24198LUX than in mice infect with 2C4-3LUX ( $<<0.0001$, $\mathrm{p}<0.0001$ and $\mathrm{p}=0.026$ respectively). These results strongly suggest that $24198 \mathrm{LUX}$ strain belonging to cc11 is responsible for a more severe systemic infection than the strain belonging to the cc18. These results indicate that the cc11 strain was able to induce an intense inflammatory response. All these data strongly suggest that the experimental infection in transgenic mice expressing human transferrin reflects different pathogenic properties of $\mathrm{Nm}$. 


\subsection{Impact of dexamethasone adjuvant treatment on the clinical evolution of}

experimental infection in hTf transgenic mice

As the cc11 isolate provoked severe infection in mice with important inflammatory response, we next evaluated the effect of using corticosteroids as an adjuvant treatment of experimental meningococcal infection in mice. Three groups of mice ( $n=12$ per group) were infected by intra-peritoneal injection of $1.2 \times 10^{7} \mathrm{CFU}$ of 24198LUX strain. At $3 \mathrm{~h}$, mice of the three groups showed similar development of the infection as viewed by dynamic imaging (Fig. 1). After $3 \mathrm{~h}$ post-infection, one group of mice received intramuscular antibiotics (AMX), the second group received both AMX and DXM while the third group received saline and was used as untreated control (See Methods). Untreated mice showed reduced survival and only $42 \%$ of mice infected with 24198LUX strain (cc11) survived when not treated while all mice that were treated by AMX and DXM survived ( $100 \%$ versus $42 \%, \mathrm{p}=0.002)$. Mice that were only treated by AMX also showed significantly higher survival when compared to untreated mice but did not differ significantly from those treated by both AMX and DXM (respectively, 91\% versus 100\%, p=0.31) (Fig. 2A). AMX-treated mice and AMX/DXM-treated mice showed better clinical scores when compared to the untreated group (Fig. 2B). Moreover, AMX/DXM-treated mice showed significantly better clinical score compared to AMX-treated mice as assessed by the vitality score after $24 \mathrm{~h}$ and $36 \mathrm{~h}$ post-infection $(\mathrm{p}=0.02, \mathrm{p}<0.0001$ respectively). Hypothermia at $24 \mathrm{~h}$ post-infection was significantly more severe in the nontreated group compared to the AMX/DXM-treated or AMX-treated groups. However, it was not significantly different between the AMX/DXM-treated mice and the AMX-treated mice $(\mathrm{p}=0.97)$ (Fig. 2C). The better clinical conditions observed for AMX/DXM-treated mice was not due to lower blood bacterial loads since it did not differ significantly $(p=0.98)$ between the two groups (AMX and AMX/DXM), at $6 \mathrm{~h}$ post-infection (3 hours after the first dose of treatment) (Supplementary Fig.S2). Moreover bacteria were rapidly cleared from the blood in 
the two groups of treated mice (before $24 \mathrm{~h}$ ) whereas bacteremia was still detectable in the non-treated group at $36 \mathrm{~h}$ of infection (Supplementary Fig.S2).

After $6 \mathrm{~h}$ of infection ( $3 \mathrm{~h}$ of treatment), dynamic bioluminescence imaging approach showed that the two groups of treated mice (AMX/DXM- or AMX-treated) showed similar total signals all over the body that were significantly lower than signals of untreated mice (Fig 1A and $1 \mathrm{~B})$.

\subsection{Impact of dexamethasone adjuvant treatment on acute phase markers during experimental infection}

We next explored the immediate modifications in blood formula and acute phase markers. All infected mice developed leucopenia and neutropenia with a nadir at $6 \mathrm{~h}$ of infection (Table 1). Profound neutropenia persisted in the untreated group at $24 \mathrm{~h}$ whereas neutrophils rate had increased in the two other treated groups. Neutrophils were not significantly higher at $24 \mathrm{~h}$ in $\mathrm{AMX} / \mathrm{DXM}$-treated mice compared to AMX-treated mice $(\mathrm{p}=0.23)$.

Inflammatory response was monitored using two acute phase proteins: Crp and Lcn2. Crp levels in blood samples were determined by ELISA. Although Crp levels increased after 6 hours post-infection, its values were significantly lower in the AMX/DXM group compared to the non-treated group $(\mathrm{p}<0.0001)$ and to the AMX-treated group $(\mathrm{p}<0.0001)$ (Table 1).

The levels of Lcn2 were also significantly lower in the AMX/DXM group at 6 hours postinfection when compared to the untreated group $(p<0.0001)$ and to the AMX group $(\mathrm{p}=0.0276)$ (Table 1 and Fig.3) following the same observed trend for Crp. Lcn2 levels decreased thereafter in all groups and remained lower in AMX/DXM-treated mice compared to untreated and AMX-treated mice at 48 hours post-infection (data not shown). The high level of inflammatory response in untreated mice infected by the cc11 isolate was also confirmed by the histological findings in the liver of cc11-infected mice. At $6 \mathrm{~h}$ post 
inoculation, hepatic lesions were important but similar in the three groups (non treated, AMXtreated and AMX/DXM-treated) and consisted of multifocal diapedesis and infiltration of neutrophils associated with minimal necrosis of hepatocytes. At $24 \mathrm{~h}$ post inoculation, hepatocellular necrosis and neutrophilic infiltration were more severe and were occasionally associated with mild thrombosis (Supplementary Fig. S3). Overall score of microscopic findings was slightly higher in non-treated mice as compared to mice treated with either AMX or AMX and DXM.

\subsection{Impact of dexamethasone adjuvant treatment on cytokine expression during experimental infection}

To further have more insights on the evolution of the infection with dexamethasone treatment, we explored the levels of pro-inflammatory and anti-inflammatory cytokines in blood samples of mice from the three groups at different time-points of the infection. IL- 6 and $\mathrm{KC}$ were nonsignificantly different in all the three groups at all time-points (Fig. 4 A and B). However, AMX/DXM-treated mice showed lower concentration of TNF- $\alpha$ at $6 \mathrm{~h}$ of infection compared to AMX-treated mice $(\mathrm{p}=0.34)$ and significant lower concentration compared to the untreated group ( $\mathrm{p}=0.04)$ (Fig. $4 \mathrm{C}$ ). Inversely, the anti-inflammatory cytokine, IL-10 appeared early in AMX/DXM-treated mice and was detected at significantly higher levels at $6 \mathrm{~h}$ of infection in AMX/DXM-treated mice compared to AMX-treated mice ( $p=0.004)$ (Fig. 4 D). IL-10 decreased thereafter in the AMX/DXM-treated mice and was no longer detected after $24 \mathrm{~h}$ post-infection. IL-10 levels were very low in the AMX-treated mice at all time-points of the infection. In non-treated mice, IL-10 was also detectable after $6 \mathrm{~h}$ of infection but continued to increase and unlike treated mice, high levels of IL-10 were observed during all time-points of the infection. 


\section{DISCUSSION}

The controversial question of the use of corticosteroids in meningococcal invasive infections remains open and the availability of a reliable animal model may offer an experimental approach to address this point in a defined system. Not only this model of transgenic mice expressing the human transferrin allows meningococci to grow but it also mimics the pathogenic potential of meningococcal isolates. Indeed, without transferrin, meningococci are unable to grow in the blood of infected mice and are rapidly cleared out [21]. A more severe infection was observed when cc11, a hyperinvasive genotype, was used. These isolates induce a strong inflammation and apoptosis during meningococcal sepsis (9). We confirmed the ability of these isolates to induce strong inflammation in mice that was reflected by strong production of pro-inflammatory cytokines ( $\mathrm{KC}$ and IL-6) concomitant to tissue damages as shown by histological analysis. Our data suggest that hyperinvasive isolates like the isolate 24198 (cc11) used in this study are responsible for bad prognosis because of the important and uncontrolled inflammatory reaction they trigger. This excessive inflammatory reaction responsible of fatal outcome of meningococcal sepsis has been known for a long time and especially concerning the TNF- $\alpha$ secretion [22]. Meningococcal isolates belonging to different genetic lineages may therefore provoke invasive infections with variable severity. Similar observations were also reported in other bacterial species as in Streptococcus pneumonia where different genotypes and capsular types determine the pathogenic behavior of pneumococci [23].

Dexamethasone as an adjuvant treatment is associated with higher survival and seems to improve the clinical manifestations of the experimental infection compared to mice only treated with AMX with a significant reduction of the acute phase proteins assessed by Crp and Lcn 2 analysis. This improvement does not seem to be due to faster bacterial clearance as no significant difference in meningococcal bacteremia was observed. However, this 
improvement could be due to the ability of corticosteroids to induce anti-inflammatory cytokines such as IL-10. In fact, the early increase of this cytokine (6 $\mathrm{h}$ after the infection and $3 \mathrm{~h}$ after the first dose of combined treatment) is in accordance with this explanation.

The interference of different treatments (saline, AMX and AMX/DXM) with the reninangiotensin-aldosterone system (RAAS) for the induction of the inflammatory response also require to be investigated [24]. Indeed, these treatments as well as the early infection in different organ (kidneys and liver) may impact on the RAAS (Supplementary Fig. S1).

The induction of these pro-inflammatory cytokines is required for optimal clearance of meningococci. However, excessive and/or uncontrolled inflammatory reaction may also lead to tissue damage as we observed in histological hepatocytes lesions.

The impact of IL-10 is clearly linked to the timing of its production. Indeed, in untreated mice late production of IL-10 may correspond to a negative feedback mechanism to limit the potential damage of inflammatory cytokines. This late production occurs upon the control of infection and therefore is not expected to impede pathogen clearance but rather improve immunopathology [25]. An earlier release of IL-10 may worsen the infection as it may preclude pathogen clearance. In the AMX/DXM-treated mice, the early production of IL-10 was advantageous because antibiotic treatment allowed rapid bacterial clearance and therefore permitted clinical benefit from the early release of IL-10. These data corroborate previous results from our laboratory that suggested that the use of corticosteroids as adjuvant treatment of meningococcal sepsis may reduce mortality and severe forms of the disease [11]. High levels of IL-10 were reported in patients with meningococcal sepsis when they reach the hospital $8 \mathrm{~h}$ to $24 \mathrm{~h}$ after the first symptoms are recognized and that it is correlated with high plasma levels of meningococcal endotoxin [26]. Nm-infected human monocytes produce high levels of pro-inflammatory cytokines (TNF- $\alpha$, IL-6 and IL-8). These levels were reduced by $36 \%$ to $58 \%$ when IL-10 was given with infecting meningococci [27]. Beneficial effect of IL- 
10 on sepsis mortality in mice have already been described [28-30] but these early beneficial effects are counterbalanced by secondary pejorative effects of those anti-inflammatory cytokines in sepsis. In fact, a phase of "immunoparalysis" might be responsible of secondary deaths in sepsis [31, 32].

\section{CONCLUIONS}

Corticosteroids administration might thus be particularly interesting by inducing early temporary secretion of IL-10 without secondary immune suppression providing that the bacterial infection is controlled by appropriate antibiotic treatment. DXM when early administered with antibiotic may have a crucial impact in early inducing IL-10 that may then protect mice from rapid overstimulation of pro-inflammatory cytokines. 


\section{ACKNOWLEDGEMENTS}

This work was supported by the Institut Pasteur, Paris. M.L. the Regional Health Agency of the Region of Paris. 


\section{REFERENCES}

[1] Bratcher HB, Bennett JS, Maiden MC. Evolutionary and genomic insights into meningococcal biology. Future Microbiol. 2012;7:873-85.

[2] Rosenstein NE, Perkins BA, Stephens DS, Popovic T, Hughes JM. Meningococcal disease. N Engl J Med. 2001;344:1378-88.

[3] Trotter CL, Fox AJ, Ramsay ME, Sadler F, Gray SJ, Mallard R, et al. Fatal outcome from meningococcal disease--an association with meningococcal phenotype but not with reduced susceptibility to benzylpenicillin. J Med Microbiol. 2002;51:855-60.

[4] Zarantonelli ML, Lancellotti M, Deghmane AE, Giorgini D, Hong E, Ruckly C, et al. Hyperinvasive genotypes of Neisseria meningitidis in France. Clin Microbiol Infect. 2008;14:467-72.

[5] Deghmane AE, Veckerle C, Giorgini D, Hong E, Ruckly C, Taha MK. Differential modulation of TNF-alpha-induced apoptosis by Neisseria meningitidis. PLoS Pathog. 2009;5:e1000405.

[6] van Deuren M, van der Ven-Jongekrijg J, Bartelink AK, van Dalen R, Sauerwein RW, van der Meer JW. Correlation between proinflammatory cytokines and antiinflammatory mediators and the severity of disease in meningococcal infections. J Infect Dis. 1995;172:4339.

[7] Prigent H, Maxime V, Annane D. Clinical review: corticotherapy in sepsis. Crit Care. 2004;8:122-9.

[8] Annane D. Corticosteroids for severe sepsis: an evidence-based guide for physicians. Ann Intensive Care. 2011;1:7.

[9] Nguyen TH, Tran TH, Thwaites G, Ly VC, Dinh XS, Ho Dang TN, et al. Dexamethasone in Vietnamese adolescents and adults with bacterial meningitis. $\mathrm{N}$ Engl $\mathrm{J}$ Med. 2007;357:2431-40.

[10] Scarborough M, Gordon SB, Whitty CJ, French N, Njalale Y, Chitani A, et al. Corticosteroids for bacterial meningitis in adults in sub-Saharan Africa. N Engl J Med. 2007;357:2441-50.

[11] Madhi F, Levy C, Deghmane AE, Bechet S, Cohen R, Taha MK. Corticosteroid Therapy in Genotype ST-11 Meningococcal Infections. Pediatr Infect Dis J. 2013;32:291-3.

[12] Szatanik M, Hong E, Ruckly C, Ledroit M, Giorgini D, Jopek K, et al. Experimental meningococcal sepsis in congenic transgenic mice expressing human transferrin. PLoS One. 2011;6:e22210.

[13] Deghmane AE, Parent du Chatelet I, Szatanik M, Hong E, Ruckly C, Giorgini D, et al. Emergence of new virulent Neisseria meningitidis serogroup C sequence type 11 isolates in France. J Infect Dis. 2010;202:247-50.

[14] Guiddir T, Deghmane AE, Giorgini D, Taha MK. Lipocalin 2 in cerebrospinal fluid as a marker of acute bacterial meningitis. BMC Infect Dis. 2014;14:276.

[15] Taha MK, Giorgini D, Nassif X. The pilA regulatory gene modulates the pilus-mediated adhesion of Neisseria meningitidis by controlling the transcription of pilC1. Mol Microbiol. 1996;19:1073-84.

[16] Zarantonelli ML, Skoczynska A, Antignac A, El Ghachi M, Deghmane AE, Szatanik M, et al. Penicillin resistance compromises Nod1-dependent proinflammatory activity and virulence fitness of Neisseria meningitidis. Cell Host Microbe. 2013;13:735-45.

[17] Huet O, Ramsey D, Miljavec S, Jenney A, Aubron C, Aprico A, et al. Ensuring animal welfare while meeting scientific aims using a murine pneumonia model of septic shock. Shock. 2013;39:488-94. 
[18] Shrum B, Anantha RV, Xu SX, Donnelly M, Haeryfar SM, McCormick JK, et al. A robust scoring system to evaluate sepsis severity in an animal model. BMC Res Notes. 2014;7:233.

[19] Angelov O, Schroer RA, Heft S, James VC, Noble J. A comparison of two methods of bleeding rats: the venous plexus of the eye versus the vena sublingualis. J Appl Toxicol. 1984;4:258-60.

[20] Kellogg DS, Jr., Peacock WL, Jr., Deacon WE, Brown L, Pirkle DI. Neisseria gonorrhoeae. I. Virulence Genetically Linked to Clonal Variation. J Bacteriol. 1963;85:12749.

[21] Zarantonelli ML, Szatanik M, Giorgini D, Hong E, Huerre M, Guillou F, et al. Transgenic mice expressing human transferrin as a model for meningococcal infection. Infect Immun. 2007;75:5609-14.

[22] Waage A, Halstensen A, Espevik T. Association between tumour necrosis factor in serum and fatal outcome in patients with meningococcal disease. Lancet. 1987;1:355-7.

[23] Sjöstrom K, Spindler C, Ortqvist A, Kalin M, Sandgren A, Kuhlmann-Berenzon S, et al. Clonal and capsular types decide whether pneumococci will act as a primary or opportunistic pathogen. Clin Infect Dis. 2006;42:451-9.

[24] Salgado DR, Rocco JR, Silva E, Vincent JL. Modulation of the renin-angiotensinaldosterone system in sepsis: a new therapeutic approach? Expert Opin Ther Targets. 2010;14:11-20.

[25] Couper KN, Blount DG, Riley EM. IL-10: the master regulator of immunity to infection. J Immunol. 2008;180:5771-7.

[26] Brandtzaeg P, Bjerre A, Ovstebo R, Brusletto B, Joo GB, Kierulf P. Neisseria meningitidis lipopolysaccharides in human pathology. J Endotoxin Res. 2001;7:401-20.

[27] Gopinathan U, Ovstebo R, Olstad OK, Brusletto B, Dalsbotten Aass HC, Kierulf P, et al. Global effect of interleukin-10 on the transcriptional profile induced by Neisseria meningitidis in human monocytes. Infect Immun. 2012;80:4046-54.

[28] Gerard C, Bruyns C, Marchant A, Abramowicz D, Vandenabeele P, Delvaux A, et al. Interleukin 10 reduces the release of tumor necrosis factor and prevents lethality in experimental endotoxemia. J Exp Med. 1993;177:547-50.

[29] Howard M, Muchamuel T, Andrade S, Menon S. Interleukin 10 protects mice from lethal endotoxemia. J Exp Med. 1993;177:1205-8.

[30] Latifi SQ, O'Riordan MA, Levine AD. Interleukin-10 controls the onset of irreversible septic shock. Infect Immun. 2002;70:4441-6.

[31] Germain RN. Maintaining system homeostasis: the third law of Newtonian immunology. Nat Immunol. 2012;13:902-6.

[32] Volk HD, Reinke P, Docke WD. Clinical aspects: from systemic inflammation to 'immunoparalysis'. Chem Immunol. 2000;74:162-77. 


\section{Figures legends}

Figure 1 Dissemination of $N$. meningitidis in BALB/c hTf transgenic mice. Mice were infected by intraperitoneal injection of $1.2 \times 10^{7} \mathrm{CFU}$ of the strain 24198LUX and treated either with amoxicillin (AMX) alone, with amoxicillin and dexamethasone (AMX + DXM) or with saline (non-treated). Mice were analyzed for bioluminescence at the indicated times using an IVIS 100 system (Xenogen Corp., Alameda, CA) that has the maximal capacity to analyse five mice at the same time. Images depict photographs overlaid with color representations of luminescence intensity, measured in total photons/sec and indicated on the scales, where red is most intense and blue is least intense. (A) Dorsal view of 5 mice infected with 24198LUX (cc11 strain) at different times post-infection and regarding three groups of treatment: one group non-treated (saline injection), one group treated with AMX and one group treated with AMX +DXM (B) Total body luminescence quantification. The luminescence was quantified and expressed as means \pm SD from each category at the indicated times by defining specific representative region of interest encompassing the entire animal. (C) Total luminescence delimitated to the skull. The luminescence was quantified and expressed as means \pm SD from each category at the indicated times by defining specific representative region of interest encompassing only the skull of the animal. $p$-value expressed are those comparing the AMX + DXM (red) group to the non-treated group (black); $* * * *=p<0.0001$. Note that after 24 hours of infection signals were not significantly different from the background (non infected mice with $10^{5}$ photons $/ \mathrm{sec}$ )

Figure 2. Clinical evolution of BALB/c hTf transgenic mice infected with $N$. meningitidis 24198LUX strain. Data from mice that were non-treated (black), treated with amoxicillin ((AMX) blue) or treated with amoxicillin and dexamethasone ((AMX + DXM) red) are displayed, with N. meningitidis 2C4-3LUX strain or non-infected. (A) Evolution of mice 
survival after infection. P-value expressed are those comparing the AMX + DXM group to the non-treated group and to the AMX-treated group. (B) Evolution of mice vitality assessed by a vitality score (ranging from 0 to 5) taking into accounts the fur aspect as well as the activity of the mice. Fur aspect ranged from 0 to 2 ( $0=$ Erection of the hair, $1=$ Hair coat appears soiled, $2=$ Hair coat appears glossy and smooth) and activity score of live mice ranged from 0 to 3 $(0=$ No resistance to traction, $1=$ Weak resistance to traction, $2=$ Strong resistance to traction, $3=$ Spontaneous forward propulsion). (C) Evolution of body temperature in ${ }^{\circ} \mathrm{C}$. (D) Evolution of weight loss in grams. $*=\mathrm{p}<0.05, * * *=\mathrm{p}<0.001, * * * *=\mathrm{p}<0.0001$.

Figure 3. Lipocalin 2 detection in blood of infected mice. Western blotting analysis using antibodies specific to mouse Lcn2. Plasma samples were collected at $6 \mathrm{~h}$ post-infection from 4 mice of each tested group. The same positive control with a known concentration was used for each Western Blot.

Figure 4. Kinetics of cytokines production in BALB/c hTf transgenic mice infected by intraperitoneal injection of $1.2 \times 10^{7} \mathrm{CFU}$ 24198LUX strain. As in Fig.1, mice were treated either with amoxicillin (AMX), with amoxicillin and dexamethasone (AMX + DXM) or with saline (non-treated). ELISA assays were used to quantify (A) IL-6, (B) KC, (C) TNF-alpha and (D) IL-10 in blood samples from mice at different time-points of infection. Data are expressed as mean of concentration for each tested cytokine after 3, 6, 24 and 36 hours (IL-6, KC and IL10). P-value expressed are those comparing the AMX + DXM group (red) to the non-treated group (black) and to the AMX-treated group (blue); * $=\mathrm{p}<0.05, * *=\mathrm{p}<0.01, * * *=\mathrm{p}<0.001$, $* * * *=\mathrm{p}<0.0001$ 
Fig.1

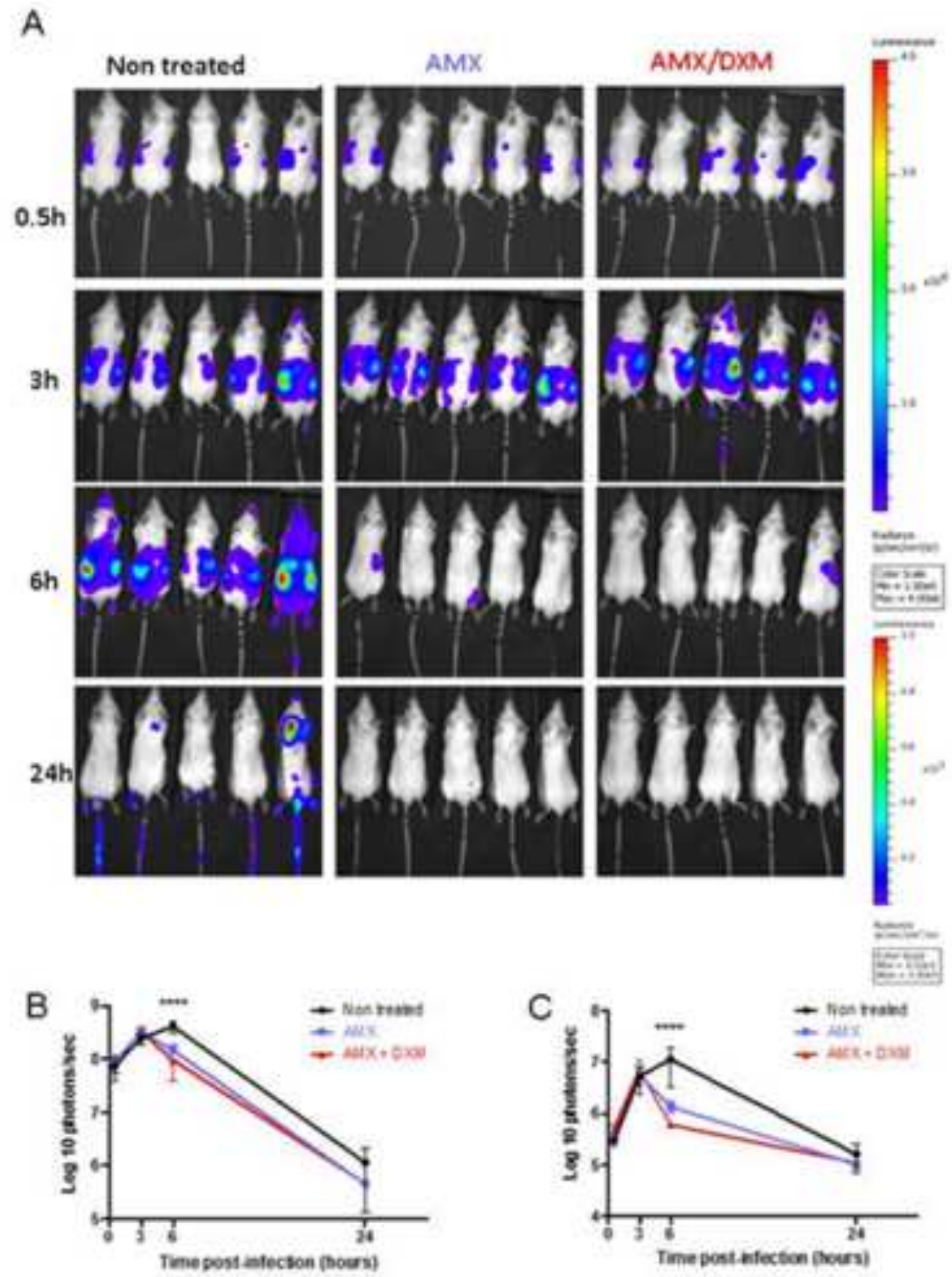


Fig. 2

A

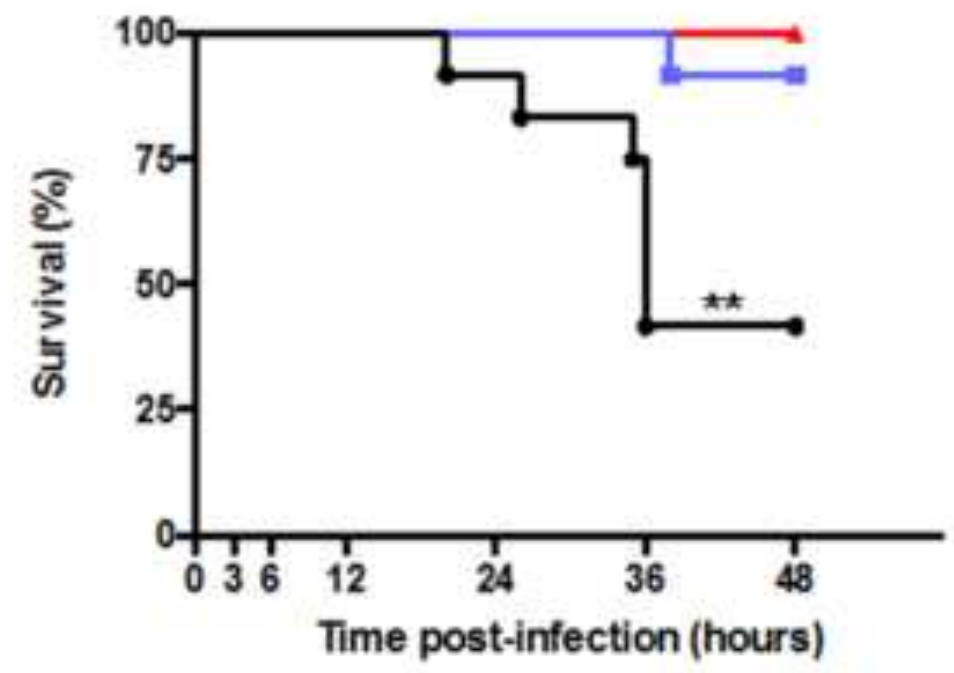

C

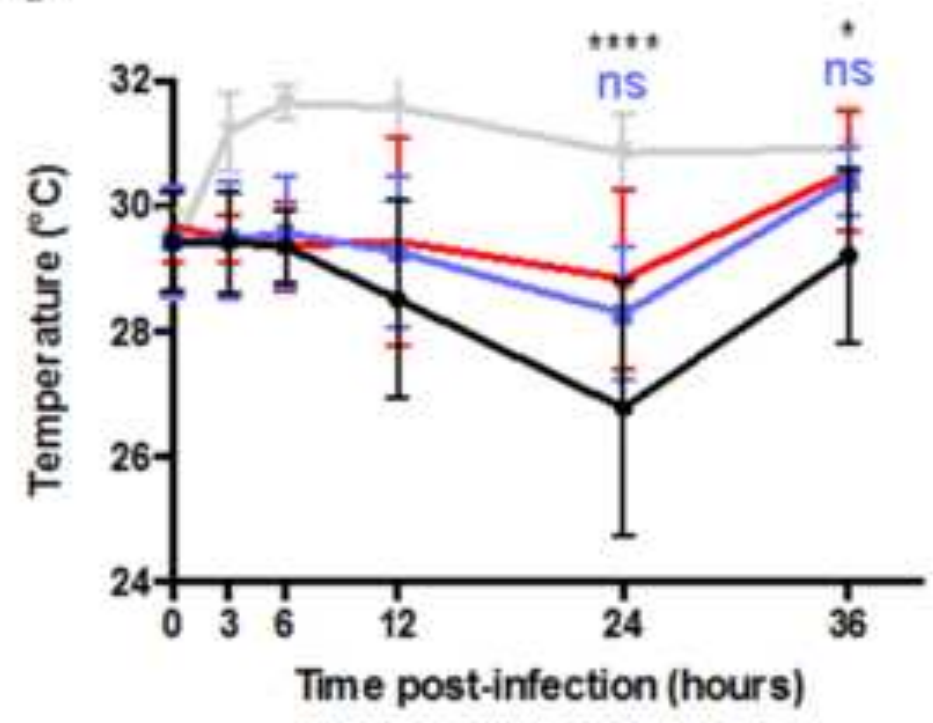

B

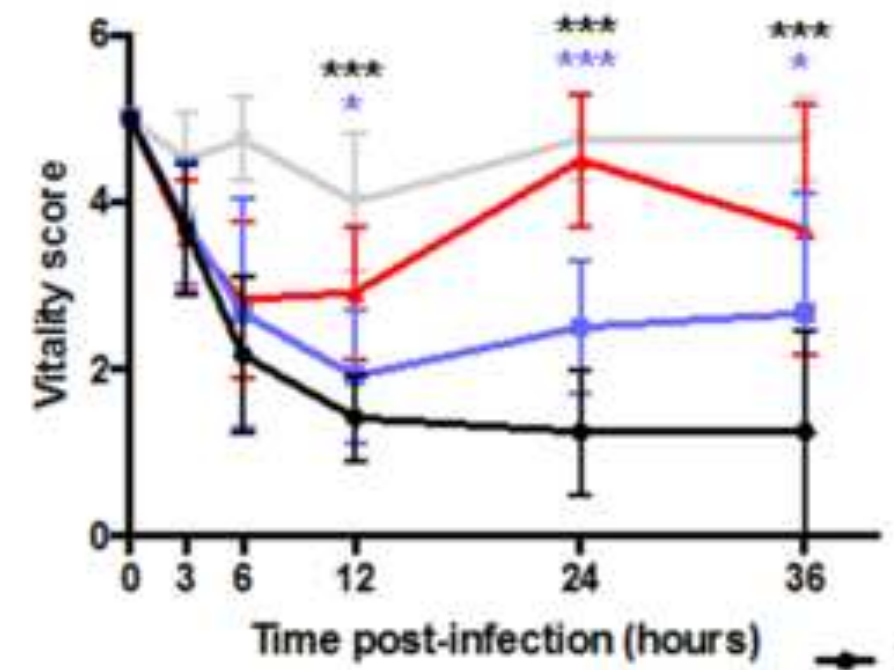

D

- 24198LUXAmoX

-24198LUXAmox + DXM

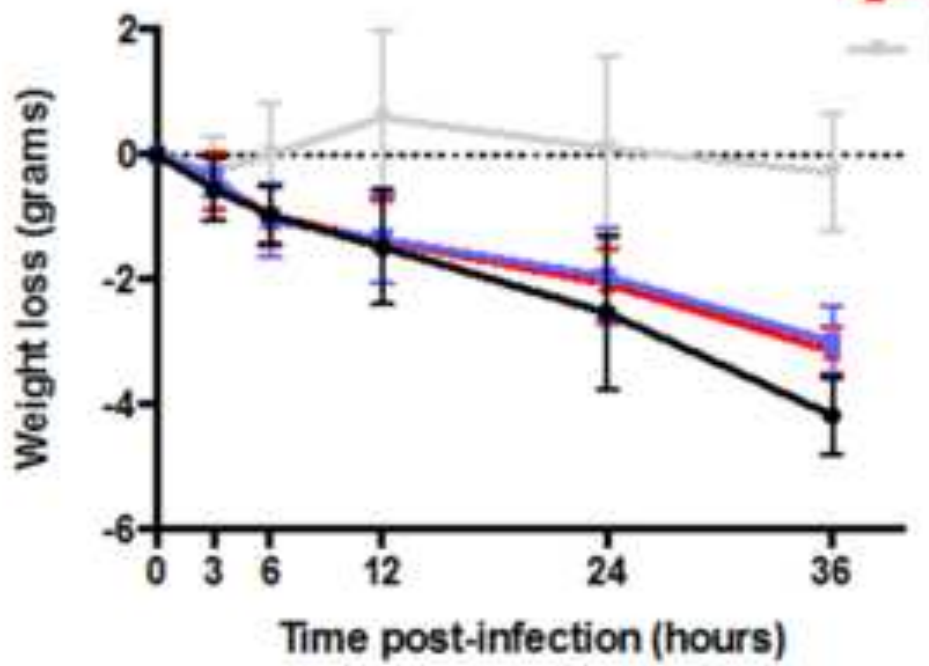


Click here to download high resolution image

\section{Fig. 3}

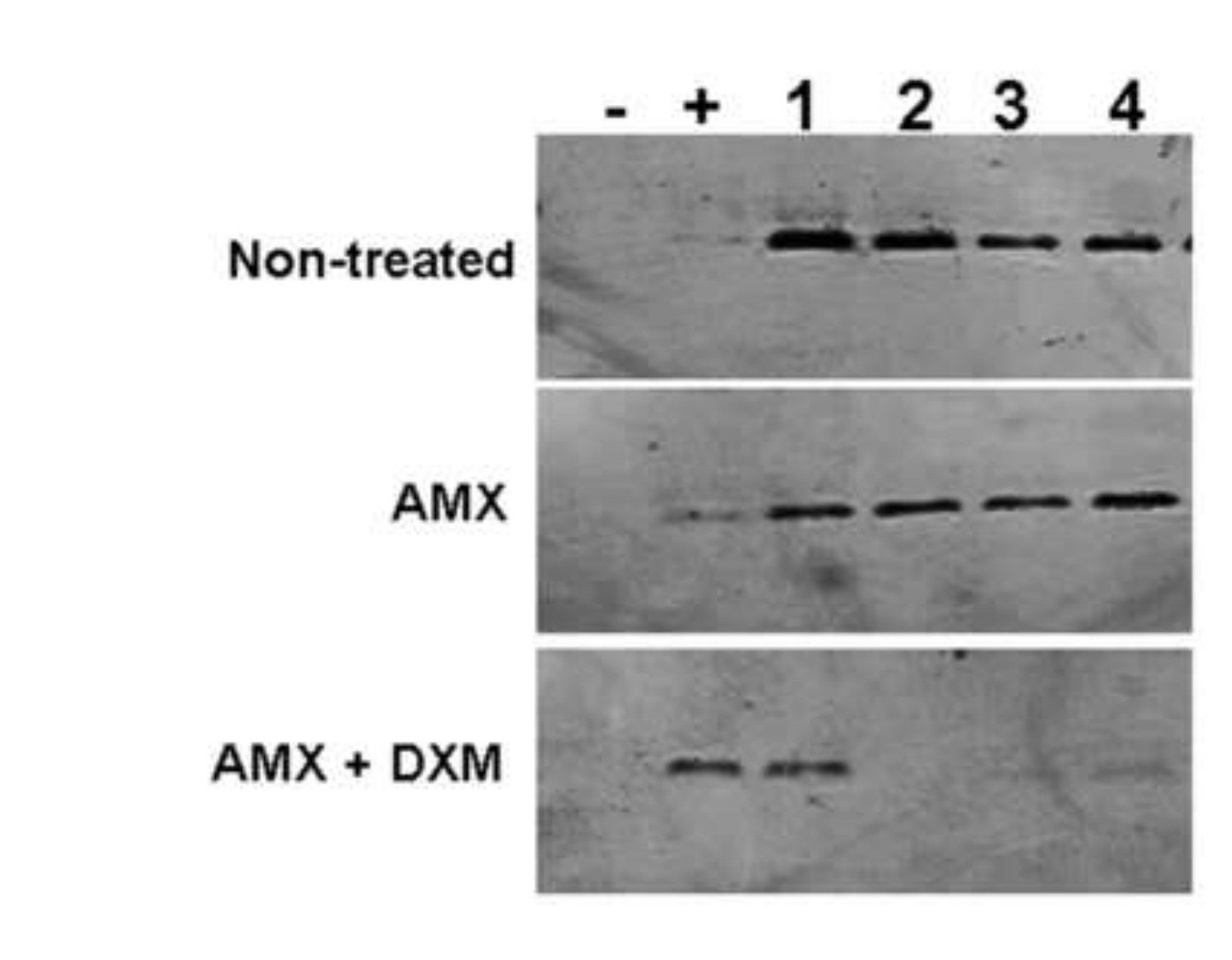


Fig.4
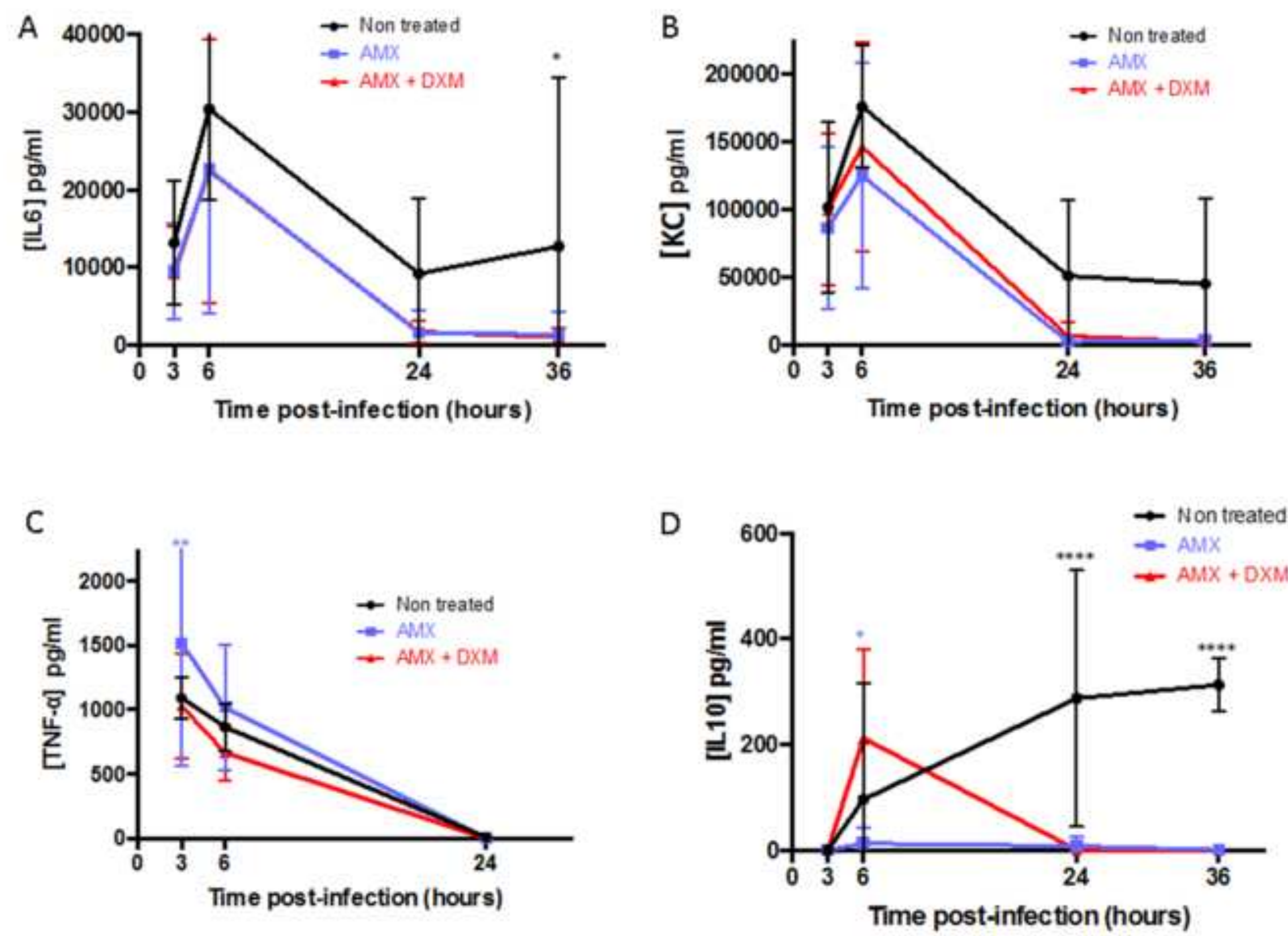
Table 1 White blood cell formulae, CRP and Lipocalin 2 levels in mice infected with $N$. meningitidis 24198LUX strain.

\begin{tabular}{|l|l|l|l|l|l|}
\hline & Time & Non treated & AMX & AMX/DXM & p values \\
\hline \multirow{2}{*}{$\begin{array}{l}\text { Polymorphonuclear } \\
\text { cells }\end{array}$} & $3 \mathrm{~h}$ & $616 \pm 231$ & $933 \pm 504$ & $1066 \pm 750$ & $\mathrm{~ns}$ \\
\cline { 2 - 6 } & $6 \mathrm{~h}$ & $416 \pm 132$ & $300 \pm 109$ & $366 \pm 51$ & $\mathrm{~ns}$ \\
\cline { 2 - 6 } & $24 \mathrm{~h}$ & $380 \pm 83$ & $1083 \pm 511$ & $1483 \pm 604$ & $\mathrm{~ns}$ \\
\hline \multirow{2}{*}{$\begin{array}{l}\text { Total white blood } \\
\text { cells }\end{array}$} & $3 \mathrm{~h}$ & $2416 \pm 685$ & $3350 \pm 1013$ & $3816 \pm 1866$ & $\mathrm{~ns}$ \\
\cline { 2 - 6 } & $6 \mathrm{~h}$ & $1683 \pm 386$ & $1050 \pm 398$ & $1633 \pm 258$ & $\mathrm{~ns}$ \\
\cline { 2 - 6 } & $24 \mathrm{~h}$ & $2060 \pm 230$ & $2783 \pm 1579$ & $3400 \pm 1454$ & $\mathrm{~ns}$ \\
\hline$(\mathrm{CRP}) \mu \mathrm{g} / \mathrm{ml}$ & $6 \mathrm{~h}$ & $10475 \pm 523$ & $10019 \pm 720$ & $5527 \pm 791$ & $<0.0001$ \\
\hline (Lcn2) ng/ml & $6 \mathrm{~h}$ & $610 \pm 79$ & $342 \pm 104$ & $104 \pm 107$ & $\begin{array}{l}*<0,0001 \\
\text { (L) }\end{array}$ \\
& & & & & \\
\hline
\end{tabular}

(Time= time post-infection, $\mathrm{AMX}=$ amoxicillin, $\mathrm{DXM}=$ dexamethasone).

$* \mathrm{p}$ value for non treated group, \# $p$ value for AMX group (AMX + DXM group is the reference). 